\title{
A CONTRIBUIÇÃO DE DONALD C. HAMBRICK PARA A TEORIA DO ALTO ESCALÃO - UM ESTUDO BIBLIOMÉTRICO
}

\author{
ID José Eduardo Valladares Teixeira \\ Mestre em Administração, Universidade Nove de Julho - UNINOVE, São Paulo, SP, Brasil. \\ j.e.teixeira@hotmail.com
}

\section{Resumo}

Objetivo: Investigar o impacto das contribuições de Donald. C. Hambrick para a Teoria do Alto Escalão (Upper Echelon Theory UET).

Abordagem: Estudo bibliométrico de citações e cocitações dos artigos que referenciam pesquisas publicadas por Donald C. Hambrick sobre o tema UET.

Resultados: Com este estudo, confirmou-se a relevância dos artigos publicados por Hambrick sobre a UET ao longo do tempo, a associação da UET a diferentes correntes teóricas no campo da Administração e identificaram-se frentes de pesquisa atuais sobre o tema.

Limitações da pesquisa: A pesquisa de citações da obra de Hambrick sobre UET foi limitada aos artigos por ele publicados em revistas acadêmicas revisadas por pares, o que eliminou da busca parte de sua produção sobre o tema. As citações aos artigos de Hambrick sobre UET foram obtidas, exclusivamente, na base ISI Web of Knowledge, que utiliza critérios declaradamente seletivos para a escolha de publicações nela indexadas.

Implicações práticas: A pesquisa identifica oportunidades de investigação adicional em temas associados à Teoria do Alto Escalão e para sua aplicação e análise em novos contextos.

Originalidade/Valor: Este é o primeiro estudo bibliométrico conhecido que compreende a análise de todos os artigos de Hambrick sobre a UET.

Palavras-chave: Donald C. Hambrick. Teoria do alto escalão. Estudo bibliométrico. Equipe de administração de topo.

DONALD C. HAMBRICK'S CONTRIBUTION TO THE UPPER ECHELON THEORY - A BIBLIOMETRIC STUDY

\section{Abstract}

Objective: Our objective was to investigate the impact of Donald C. Hambrick's contributions to the Upper Echelon Theory (UET). Approach: A bibliometric study of citations and co-citations in articles which refer to research published by the author on UET. Results: In this study, we confirmed the relevance of articles published by Hambrick on the UET over time, revealed the association of the UET with different theoretical currents in Management and identified current research fronts on the subject. Limitations: The search for citations to Hambrick's work on UET was limited to articles published in peer-reviewed academic journals, which eliminated part of the author's research on the subject. We obtained the citations to Hambrick's articles on UET exclusively from the ISI Web of Knowledge database, which uses highly selective criteria for choosing indexed publications indexed. Practical implications: Based on the results, we point out opportunities for further investigation into topics regarding Upper Echelons Theory, application and analysis in new contexts.

Originality / Relevance: This is the first known bibliometric study to analyze all Hambrick's articles on the UET.

Keywords: Donald C. Hambrick. Upper echelon theory. Biblimetrics. Top management team.

\section{CONTRIBUCIÓN DE DONALD C. HAMBRICK A LA TEORÍA DE LOS ESCALALFONES SUPERIORES - UN ESTUDIO BIBLIOMÉTRICO}

\begin{abstract}
Resumen
Objetivo: Investigar el impacto de las contribuciones de Donald. C. Hambrick para la teoría de los escalafones superiores - UET.

Enfoque: Estudio bibliométrico de citas y co-citas de artículos que hacen referencia a investigaciones publicadas por Donald C. Hambrick sobre el tema de la UET.

Resultados: Con este estudio, se confirmó la relevancia de los artículos publicados por Hambrick sobre UET a lo largo del tiempo, la asociación de UET con diferentes corrientes teóricas en el campo de la Administración, y se identificaron los frentes de investigación actuales sobre el tema.

Limitaciones de la investigación: La búsqueda de citas del trabajo de Hambrick en UET se limitó a los artículos que publicó en revistas académicas revisadas por pares, lo que eliminó parte de su investigación sobre el tema de la búsqueda. Las citas de los artículos de Hambrick sobre UET se obtuvieron exclusivamente de la base de datos de ISI Web of Knowledge, que utiliza criterios declaradamente selectivos para la elección de publicaciones indexadas en ella.

Implicaciones prácticas: La investigación identifica oportunidades para futuras investigaciones sobre temas asociados con la teoría de los escalafones superiores y para su aplicación y análisis en nuevos contextos.

Originalidad / Valor: Este es el primer estudio bibliométrico conocido que incluye el análisis de todos los artículos de Hambrick sobre la UET.
\end{abstract}

Palabras clave: Donald C. Hambrick. Teoría de los escalafones superiores. Estudio bibliométrico. Equipo de alta dirección.

Teixeira, J. E. V. (2020). A contribuição de Donald C. Hambrick para a teoria do alto escalão - um estudo bibliométrico. Iberoamerican Journal of Strategic Management (IJSM), 19(2), 143-165. https://doi.org/10.5585/riae.v19i2.14593. 


\section{Introdução}

Ao longo das últimas décadas, uma questão tem ocupado a atenção de muitos pesquisadores: qual a contribuição dos gestores de alto nível para os resultados das organizações? Diversas perspectivas têm sido utilizadas para responder a essa questão. Teóricos da ecologia organizacional (Hannan \& Freeman, 1977) e da nova teoria institucional (DiMaggio \& Powell, 1983) defendem que as forças do ambiente, a cultura predominante e a história prévia das organizações tornam a influência dos administradores sobre os destinos e resultados das organizações necessariamente limitada. Outros pesquisadores, embora reconheçam o papel dos gestores de alto nível no direcionamento das ações das empresas, concluem que uma lógica técnico-econômica os impele a decisões racionais, nas quais as opções pessoais encontram um campo restrito para sua expressão (Harrigan, 1980; Porter, 1980).

Em oposição às correntes que atribuem um papel de pouco destaque para os gestores, a perspectiva da "escolha estratégica", por exemplo, identifica que as características das organizações, como sua estratégia, estrutura, processos e, em última análise, desempenho, são fortemente influenciadas por atores humanos e, em particular, seus executivos de alto nível (Child, 1972; 1997). No movimento chamado Carnegie School, o estudo da tomada de decisão em organizações ocupa um papel central. Seus pesquisadores argumentam que as decisões dos administradores são fortemente influenciadas não apenas por uma busca automática de resultados econômicos superiores, mas também, e em larga medida, por um conjunto de fatores comportamentais e características pessoais dos indivíduos por elas responsáveis (March \& Simon, 1958; Cyert \& March, 1963; Gavetti, Levinthal \& Ocasio, 2007). Aspectos como a racionalidade limitada, objetivos múltiplos e conflitantes, múltiplas opções e aspirações pessoais afetam a capacidade de tomar decisões dos gestores. De acordo com esses teóricos, quanto mais complexas as decisões, mais os aspectos comportamentais são relevantes e mais essas decisões refletem as idiossincrasias dos indivíduos envolvidos.

A Teoria do Alto Escalão (Upper Echelon Theory - UET), conceituada inicialmente no artigo seminal de Hambrick e Mason (Hambrick \& Mason, 1984), tem sua origem nesta última perspectiva, que atribui aos executivos de alto nível grande importância nos destinos das organizações. Desde sua publicação, o artigo de 1984 tem servido de ponto de partida para um grande número de estudos que focalizam a influência dos executivos de topo. De acordo com Carpenter, Geletkanycz e Sanders (2004), até 2004, mais de 500 citações tinham sido feitas ao artigo de Hambrick e Mason, comprovando seu impacto. Uma pesquisa recente, realizada na base de dados ISI Web of Science (Core Collection), identificou mais de 4.400 citações, indicando que sua importância não diminuiu com o passar dos anos.

Um dos pesquisadores que contribuiu para o desenvolvimento da UET foi o próprio Donald C. Hambrick, que, isoladamente ou com coautores, publicou número expressivo de estudos sobre o tema. Artigos já publicados, como os de Carpenter, Geletkanycz e Sanders (2004), Hambrick (2007) e Oppong (2014) revisitam a UET, seus avanços e desdobramentos - nos quais os trabalhos de Hambrick têm grande relevância - e apontam aspectos da teoria ainda pouco explorados. No entanto, as revisões 
conhecidas não compreendem uma investigação de toda obra de Hambrick sobre a UET. Considerando essa lacuna, formulamos a seguinte questão de pesquisa: qual a contribuição de Donald C. Hambrick para o estudo da UET e quais suas ramificações em campos correlatos da Administração, em particular da estratégia empresarial? Para respondê-la, realizamos o estudo dos artigos que citam o autor, por meio de uma análise bibliométrica, que é uma técnica que permite identificar a essência da contribuição de um autor e analisar as ligações da sua obra com a de outros autores e temas (Ramos-Rodrígues \& RuízNavarro, 2004).

Este artigo provê uma perspectiva sobre a influência de Donald C. Hambrick para os estudos de UET ao longo das últimas décadas, corroborando a relevância da contribuição desse autor para a pesquisa do tema. Este trabalho também identifica as correntes teóricas associadas à UET, que são utilizadas pelos autores que citam Hambrick, contribuindo para elucidar as relações entre os campos teóricos, nos quais as pesquisas em UET encontram suporte. Finalmente, com esta pesquisa, indicamse oportunidades para investigações futuras, que podem ampliar o conhecimento da sobre essa estrutura teórica sobre o qual a UET está construída.

Após esta introdução, este artigo está estruturado da seguinte forma: inicialmente, apresentamos os conceitos da UET. A seguir, expomos a metodologia de pesquisa e os procedimentos de coleta de dados. Depois, descrevemos e analisamos os resultados alcançados, que precedem uma apresentação das conclusões do estudo. Finalmente, apresentamos, ao final do artigo, uma discussão das suas limitações e sugestões de temas para pesquisa futura.

\section{A Teoria do Alto Escalão}

A Upper Echelon Theory (UET), tal como exposta no artigo de Hambrick e Mason (1984), tem como base dois preceitos principais: 1) os executivos agem com base na sua intepretação pessoal das situações estratégicas que enfrentam, e 2) essas interpretações personalizadas são derivadas de suas experiências, valores e personalidades (Hambrick, 2007, p. 334). Os resultados organizacionais são fortemente influenciados pelos valores e bases cognitivas dos atores mais importantes na organização, identificados como os membros de sua equipe de alta liderança.

Duas ideias adicionais são também apresentadas no artigo, as quais complementam os preceitos principais da teoria (Hambrick, 2007). A primeira ideia é a proposta de que um foco sobre as características da equipe de administração de topo (Top Management Team - TMT) pode prover uma explicação mais completa dos resultados organizacionais do que uma ênfase restrita somente às características do executivo principal (Chief Executive Officer - CEO). Isso ocorre porque, para os autores, a liderança de uma organização complexa é uma atividade compartilhada, na qual as capacidades cognitivas, competências e interações de todos os integrantes da equipe de topo contribuem para os comportamentos estratégicos e para as tomadas de decisões. 
A segunda ideia adicional deste artigo é a de que características demográficas, como idade, tempo de mandato, educação e experiência funcional podem ser usadas como substitutos (proxies) adequados dos quadros cognitivos dos executivos de alto escalão, em face da dificuldade para obtenção de seus dados psicométricos. Mesmo reconhecendo que o uso dessas características (em oposição à identificação direta dos quadros cognitivos dos membros do TMT) não permite abrir a "caixa preta" dos processos fundamentais que acionam o comportamento dos executivos (Lawrence, 1997), os autores consideram que essas características demográficas podem ser utilizadas para se preverem as ações estratégicas de uma organização, mesmo que de forma imperfeita (D’Aveni, 1990; Eisenhardt \& Bourgeois, 1988). O modelo original da UET é apresentado na Figura 1 a seguir.

Figura 1 - O modelo original proposto para a UET

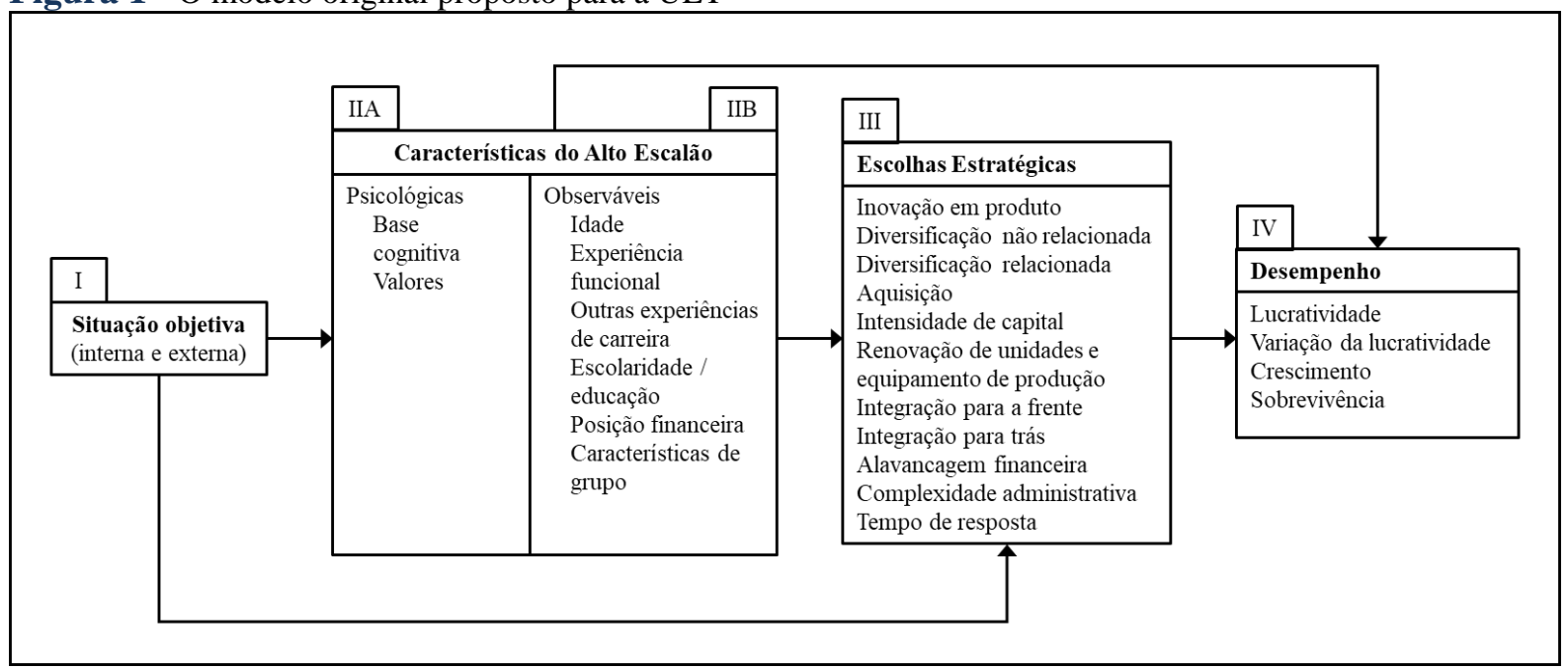

Fonte: Hambrick e Mason (1984) p. 98.

A Figura 1 apresenta a situação objetiva interna e externa da organização (I), que é interpretada pela equipe de alto escalão da empresa. Essa interpretação é influenciada pelas características dessa equipe (II), que incluem sua base cognitiva e valores (IIA). Dada a dificuldade para a identificação das características psicológicas dos executivos, características demográficas observáveis, como idade, sexo, ou experiência funcional prévia (IIB) são utilizadas para inferir os aspectos psicológicos que orientam suas escolhas quanto a alternativas estratégicas (strategic choices). A equipe de alto escalão pode escolher diferentes estratégicas para o enfrentamento dos desafios da organização, que incluem desde inovação em produtos até (a redução do) tempo de resposta (III). Finalmente, os resultados organizacionais, medidos por meio de indicadores de desempenho (IV), serão consequência das alternativas estratégicas adotadas para a situação objetiva da organização, cuja escolha, por sua vez, foi influenciada pelas características da equipe de alto escalão.

Mais recentemente, diversos refinamentos foram adicionados à construção original da UET, nos quais se incluem a consideração dos efeitos moderadores da discrição gerencial (managerial discretion) e das demandas sobre o trabalho do executivo (executive job demands). O primeiro moderador é a discrição gerencial (managerial discretion - MD) dos gestores de alto escalão. A MD, como conceituada 
por Hambrick e Finkelstein (1987) (ver também Wangrow, Schepker, \& Baker, 2015), significa a liberdade de ação que os executivos têm para tomar suas decisões. Ela existe quando há múltiplas alternativas plausíveis para a tomada de decisão, quando esta não é submetida a restrições. A MD emana das condições ambientais (do contexto em que a organização atua), de fatores encontrados na própria organização (como sua estrutura de controle) e das características dos próprios executivos (como sua tolerância à ambiguidade). Por um lado, o conceito é introduzido na UET para servir de ponte entre a discordância histórica entre a ecologia organizacional (Hannan \& Freeman, 1977) e a nova teoria institucional (DiMaggio \& Powell, 1983). Por um lado, estabelece também uma ponte entre a perspectiva da escolha estratégica (Child, 1972; 1997), quanto à influência dos gestores de primeiro nível sobre os destinos de suas organizações, e o domínio ambiental em que competem. A influência das equipes de alto escalão é afetada (moderada) pela sua MD, pois, na presença de nível elevado de $\mathrm{MD}$, as características da equipe de gestão se refletirão mais fortemente na estratégia e no desempenho da organização. Em sentido inverso, se o corpo gerencial dispõe de reduzida MD, as características dos gestores influenciam pouco. Estudos empíricos conduzidos por Hambrick, em conjunto com outros pesquisadores (Finkelstein \& Hambrick, 1990; Crossland \& Hambrick, 2007), demonstraram o efeito moderador da MD sobre a influência do alto escalão.

Outro efeito moderador identificado para as predições da UET, desta vez por Hambrick, Finkelstein e Mooney (2005), decorre das demandas sobre o trabalho dos executivos. Os autores propõem que essas demandas decorrem de três fatores: desafios de suas tarefas (isto é, dificuldades impostas pelo contexto de sua organização), desafios de desempenho (impostos pelos proprietários ou pelo Conselho de Administração) e aspirações pessoais. Executivos submetidos a uma sobrecarga de fortes demandas serão forçados a tomar atalhos nos seus processos decisórios e a empregar alternativas, com as quais se sintam confortáveis e/ou que já experimentaram no passado, o que implica maior influência da sua trajetória prévia e inclinações pessoais nas decisões tomadas. Ao contrário, uma equipe de alto escalão que enfrenta demandas de menor intensidade pode realizar análises mais detalhadas tanto da situação enfrentada quanto das alternativas disponíveis. Esse fato aumenta a possibilidade da adoção de um curso de ação que melhor se adéqua à realidade objetiva enfrentada pela organização. Portanto, esse movimento é menos influenciado pelas características idiossincráticas dos profissionais envolvidos. O construto demandas sobre o trabalho dos executivos ainda não foi, contudo, objeto de muitos estudos que comprovem seu efeito moderador sobre as prescrições da UET.

\section{Método}

A bibliometria realizada, neste artigo, segue o modelo proposto por Ramos-Rodrígues e RuízNavarro (2004), para a análise da evolução de um campo de pesquisa, e os passos metodológicos utilizados por Ferreira, Pinto, Serra e Santos (2013), para o estudo da contribuição de John Dunning na pesquisa de negócios internacionais. Identificaram-se, em primeiro lugar, os artigos científicos 
publicados por Hambrick, que tratam da UET. Em seguida, buscamos as obras publicadas que citam estudos de autoria de Hambrick, abordando a UET. A pesquisa bibliométrica abrangeu os estudos que citam Hambrick, procurando identificar, via análise de citações, a relevância dos estudos do autor ao longo do tempo, e, por meio da análise de cocitações, as conexões e os pilares conceituais e teóricos comuns dos autores que citam Hambrick e a UET (Vogel \& Gütter, 2013; Zupic \& Cater, 2015).

A página pessoal de Hambrick no website do Smeal College of Business da Pennsylvania State University (PSU), no qual é atualmente Evan Pugh Professor e Smeal Chaired Professor of Management, contém a relação de todas as suas publicações, desde a primeira, datada de 1980 (Snow \& Hambrick, 1980). Essas publicações foram revisadas e aquelas pertinentes à UET e a temas conexos (como TMT, CEO, MD) foram identificadas, resultando em 85 observações (de um total de 126 publicações, por ocasião da busca). É importante notar que as contribuições de Hambrick para a UET começam antes mesmo da publicação do artigo seminal de 1984 (Hambrick \& Mason, 1984): os primeiros artigos identificados como pertinentes à UET são datados de 1981 (Hambrick, 1981a; 1981b, 1981c).

As publicações de Hambrick relacionadas à UET incluem comentários editoriais, introduções, artigos, relatório, capítulos em livros e livros. Contudo, optamos por buscar somente as citações aos artigos científicos publicados por Hambrick em revistas acadêmicas revisadas por pares, considerando que esses artigos representam, conforme Ramos-Rodríguez e Ruíz-Navarro (2004) o conhecimento certificado (certified knowledge). Aplicando esse critério de seleção mais restritivo, a obra publicada de Hambrick voltada para a UET somou 54 artigos. A tabela apresentada no arquivo suplementar (disponível em https://osf.io/vx5nz/?view_only=bb1b60757eb74052ac28326f1f8431e2) relaciona os artigos que foram considerados na pesquisa bibliométrica.

As citações a esses 54 artigos foram buscadas entre os artigos científicos indexados na base ISI Web of Science, serviço considerado como a fonte mais frequentemente utilizada para obtenção de dados bibliográficos (Zupic \& Carter, 2015). A pesquisa foi restrita a artigos indexados nessa base, classificados nas categorias Management ou Business. Para a análise de citações, o período considerado foi 1981, ano da primeira publicação de um artigo de Hambrick sobre o tema UET (TMT), até 2017, inclusive. Os dados obtidos da base ISI Web of Science foram processados com uso do software Excel.

Para a análise de cocitações, a pesquisa foi restrita a: 1) artigos indexados na base ISI Web of Science, classificados nas categorias Management ou Business; 2) artigos publicados em 32 revistas com fator de impacto igual ou superior a 1,4 (conforme o Journal Citation Reports de 2016), e 4), nos anos de 2016 e 2017. Esta seleção foi determinada após diversas simulações de extrações na base ISI Web of Science, até a obtenção de um número de artigos considerado adequado para manipulação nos aplicativos que suportaram este estudo. Dessa extração, resultou uma lista de 437 artigos, que totalizam 45.769 citações. Os dados obtidos foram processados usando o software Bibexcel, com o qual geramos uma matriz de cocitação, seguindo o procedimento proposto em Ramos-Rodriguez e Ruiz-Navarro (2004). A análise fatorial exploratória, suportada pelo software SPSS, foi utilizada para identificação 
Teixeira, J. E. V. (2020). A contribuição de Donald C. Hambrick para a teoria do alto escalão - um estudo bibliométrico

dos principais fatores, nos quais o conjunto de artigos cocitados se agrupam. O mapeamento de rede dos principais trabalhos cocitados foi feito com o uso do software UCINET.

\section{Resultados da bibliometria}

\section{Citações}

Identificamos, na base ISI Web of Science, 7.524 citações aos artigos de Hambrick sobre a UET, publicados no período de 1981 a 2017. A Tabela 1 relaciona, dos 54 artigos de Hambrick que abordam a UET, os 20 que foram objeto do maior número de citações no período.

Tabela 1 - Artigos de Hambrick sobre UET mais citados

\begin{tabular}{|c|c|c|}
\hline $\begin{array}{c}\text { Ano de } \\
\text { publicação }\end{array}$ & Título & Citações \\
\hline 1984 & Upper echelons: the organization as a reflection of its top managers & 1.780 \\
\hline 1990 & $\begin{array}{l}\text { Top management team tenure and organizational outcomes: the moderating } \\
\text { role of managerial discretion }\end{array}$ & 420 \\
\hline 2007 & Upper echelon theory: an update & 401 \\
\hline 1996 & $\begin{array}{l}\text { The influence of top management team heterogeneity on firms' competitive } \\
\text { moves }\end{array}$ & 361 \\
\hline 1997 & Explaining the premiums paid for large acquisitions: evidence of CEO hubris & 274 \\
\hline 1993 & Top executive commitment to the status quo: some tests of its determinants & 267 \\
\hline 1992 & Diversification posture and the characteristics of the top management team & 251 \\
\hline 1997 & $\begin{array}{l}\text { The external ties of top executives: implications for strategic choice and } \\
\text { performance }\end{array}$ & 239 \\
\hline 1991 & The seasons of a CEO's tenure & 201 \\
\hline 2007 & $\begin{array}{l}\text { It's all about me: narcissistic chief executive officers and their effects on } \\
\text { company strategy and performance }\end{array}$ & 197 \\
\hline 1981 & Environment, strategy, and power within top management teams & 168 \\
\hline 1982 & Environmental scanning and organizational strategy & 159 \\
\hline 2005 & $\begin{array}{l}\text { Factional groups: a new vantage on demographic faultlines, conflict and } \\
\text { disintegration in work teams }\end{array}$ & 155 \\
\hline 2006 & $\begin{array}{l}\text { Attention as the mediator between top management team characteristics and } \\
\text { strategic change: the case of airline deregulation }\end{array}$ & 154 \\
\hline 1989 & $\begin{array}{l}\text { Chief executive compensation: a study of the intersection of markets and } \\
\text { political processes }\end{array}$ & 146 \\
\hline
\end{tabular}




\begin{tabular}{|l|l|l|}
\hline 1988 & A model of CEO dismissal & 137 \\
\hline 1992 & $\begin{array}{l}\text { Top management team deterioration as part of the downward spiral of large } \\
\text { bankruptcies }\end{array}$ & 132 \\
\hline 1993 & $\begin{array}{l}\text { Relative standing: a framework for understanding departures of acquired } \\
\text { executives }\end{array}$ & 123 \\
\hline 2007 & $\begin{array}{l}\text { Swinging for the fences: the effects of CEO stock options on company risk- } \\
\text { taking and performance } \\
\text { Executive job demands: new insights for explaining strategic decisions and } \\
\text { leader behaviors }\end{array}$ & 120 \\
\hline 2005 & & 113 \\
\hline
\end{tabular}

Fonte: ISI Web of Science.

A Tabela 1 traz o número de citações aos artigos de Hambrick sobre UET ao longo dos anos. Nota-se que, a partir de 2005, os artigos de Hambrick sobre UET foram citados não menos de 171 vezes por ano. O ano com o maior número de citações foi 2016, com 897 citações.

Figura 2 - Citações a artigos de Donald. C. Hambrick sobre UET por ano

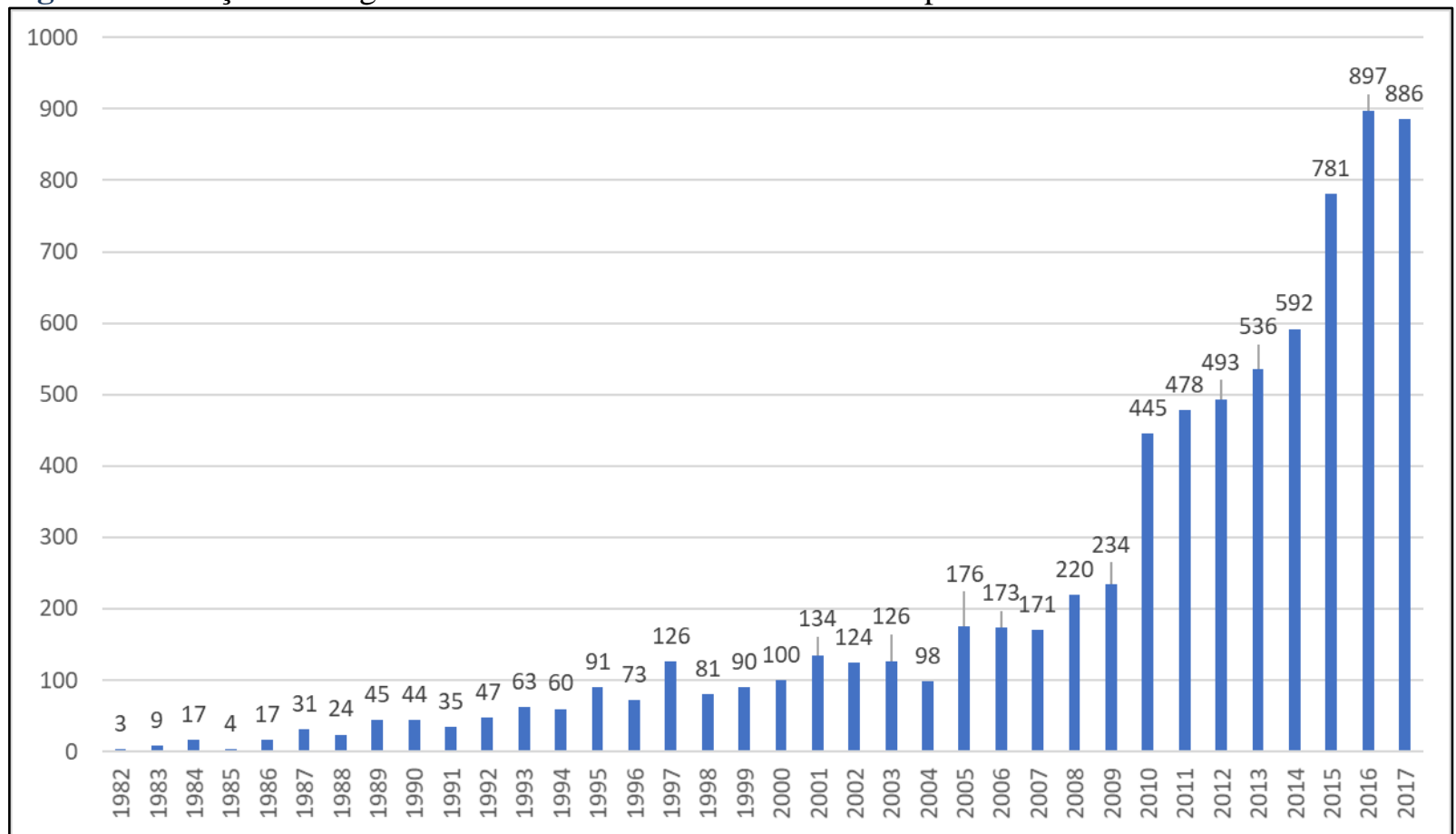

Fonte: ISI Web of Science.

As citações à obra de Hambrick sobre a UET foram feitas em 4.356 artigos, publicados em 315 periódicos acadêmicos. A Tabela 2 apresenta as 20 revistas com maiores quantidades de artigos que citam os trabalhos de Hambrick sobre UET. 
Tabela 2 - Periódicos com mais artigos que citam trabalhos de Hambrick sobre a UET

\begin{tabular}{|l|l|l|l|}
\hline \multicolumn{1}{|c|}{ Periódico } & $\mathbf{N}^{\mathbf{0}}$ de artigos & $\begin{array}{c}\text { Fator de } \\
\text { Impacto }\end{array}$ & $\begin{array}{c}\text { Início da } \\
\text { publicação }\end{array}$ \\
\hline Strategic Management Journal & 389 & 4.461 & 1980 \\
\hline Academy of Management Journal & 286 & 7.417 & 1958 \\
\hline Journal of Management & 156 & 7.733 & 1975 \\
\hline Journal of Business Research & 152 & 3.354 & 1973 \\
\hline Journal of Management Studies & 136 & 3.962 & 1964 \\
\hline Journal of Business Ethics & 131 & 2.354 & 1982 \\
\hline Organization Science & 125 & 2.691 & 1990 \\
\hline Academy of Management Review & 97 & 9.408 & 1976 \\
\hline Leadership Quarterly & 78 & 3.094 & 1990 \\
\hline Administrative Science Quarterly & 78 & 4,929 & 1956 \\
\hline Journal of Business Venturing & 76 & 5.774 & 1985 \\
\hline Management Decision & 65 & 1.396 & 1967 \\
\hline International Journal of Human Resource Management & 60 & 1.65 & 1990 \\
\hline Entrepreneurship Theory and Practice & 59 & 4.916 & 1976 \\
\hline Corporate Governance - An International Review & 57 & 2.753 & 1993 \\
\hline British Journal of Management & 56 & 2.982 & 1990 \\
\hline International Business Review & 53 & 1992 \\
\hline Human Relations & 48 & 1947 \\
\hline Journal of Applied Psychology & 52.476 & 1917 \\
\hline Journal of World Business & & 1965 \\
\hline
\end{tabular}

Fonte: ISI Web of Science.

A Tabela 2 indica que, desde os primeiros trabalhos de Hambrick sobre a UET, ocorre uma publicação contínua de artigos que referenciam essa teoria, com números crescentes de citações ao longo dos anos. Os artigos mais citados de Hambrick são os que podem ser considerados "centrais" para o desenvolvimento e formulação da UET. Em destacado primeiro lugar, aparece o artigo seminal escrito com Phyllis Mason, em que os autores sintetizam e sistematizam a "perspectiva do alto escalão" (Hambrick \& Mason, 1984). Em segundo lugar no número de citações, aparece o artigo que Hambrick escreveu com Sidney Finkelstein (Finkelstein \& Hambrick, 1990), que introduz o conceito da discrição gerencial (managerial discretion - MD), que é considerado, pelo próprio Hambrick em artigo posterior (Hambrick, 2007), como um importante moderador do poder preditivo da UET. Este último artigo de 
2007 é o terceiro mais citado, e escrito por Hambrick em resposta a uma solicitação do editor da Academy of Management Review (AMR), para uma reflexão sobre os avanços da UET desde a publicação do artigo original de 1984. O artigo deveria ainda indicar oportunidades para pesquisas futuras (Kilduff, 2007).

Nem todos os desenvolvimentos teóricos associados à UET tiveram, contudo, o mesmo impacto na academia. No artigo de 2007, Hambrick menciona outro moderador importante para a UET: o efeito das demandas sobre o trabalho do executivo (executive job demands), introduzido em artigo de sua autoria, juntamente com Sydney Finkelstein e Ann Mooney (Hambrick et al., 2005). A análise das citações aponta que este último conceito, no entanto, não parece ter tido impacto similar ao da MD, pois o artigo em que é apresentado aparece apenas como o vigésimo mais citado.

\section{Cocitações - análise fatorial exploratória}

As referências dos artigos que citam Hambrick obtidos da base ISI Web of Science foram processadas no aplicativo Bibexcel, para a geração da matriz de cocitações. Neste trabalho, eventuais erros na indexação de títulos, nomes de autores, nomes, volumes e números de periódicos nas referências aos artigos que citaram Hambrick foram corrigidos. Os 70 artigos mais cocitados, identificados no Bibexcel, que correspondem a 5\% do total de artigos cocitados, foram selecionados para a análise fatorial subsequente (Potter, 1981).

Usamos a análise fatorial exploratória para a identificação dos grupos de artigos, adotando-se as recomendações de Hair, Black, Babin, Anderson e Tatham (2009). A análise de componentes principais foi selecionada como método de extração, juntamente com a rotação Varimax. Essa análise foi realizada iterativamente, com autovalores acima de 1 como critério de retenção de fatores. Para a alocação dos artigos aos fatores, foram considerados apenas aqueles com cargas fatoriais maiores que 0,5 e que, simultaneamente, não apresentassem cargas próximas em outros fatores - caso contrário, excluía-se o artigo e fazia-se uma nova rodada. Também foram excluídos da análise artigos e livros cocitados que tratavam de métodos estatísticos ou de pesquisa científica, como o livro de Aiken e West (1991) sobre regressão múltipla e o artigo de Podsakoff, MacKenzie, Lee e Podsakoff (2003), que trata de vieses (bias) em pesquisa comportamental. Seguindo todos esses procedimentos, restaram seis fatores responsáveis pela explicação de 74,33\% da variância total da amostra, para um KMO de 0,843, que agrupam os 38 artigos remanescentes (mantidos após as exclusões). A Tabela 3 apresenta o resultado da análise. 
Tabela 3 -Análise fatorial exploratória dos artigos cocitados

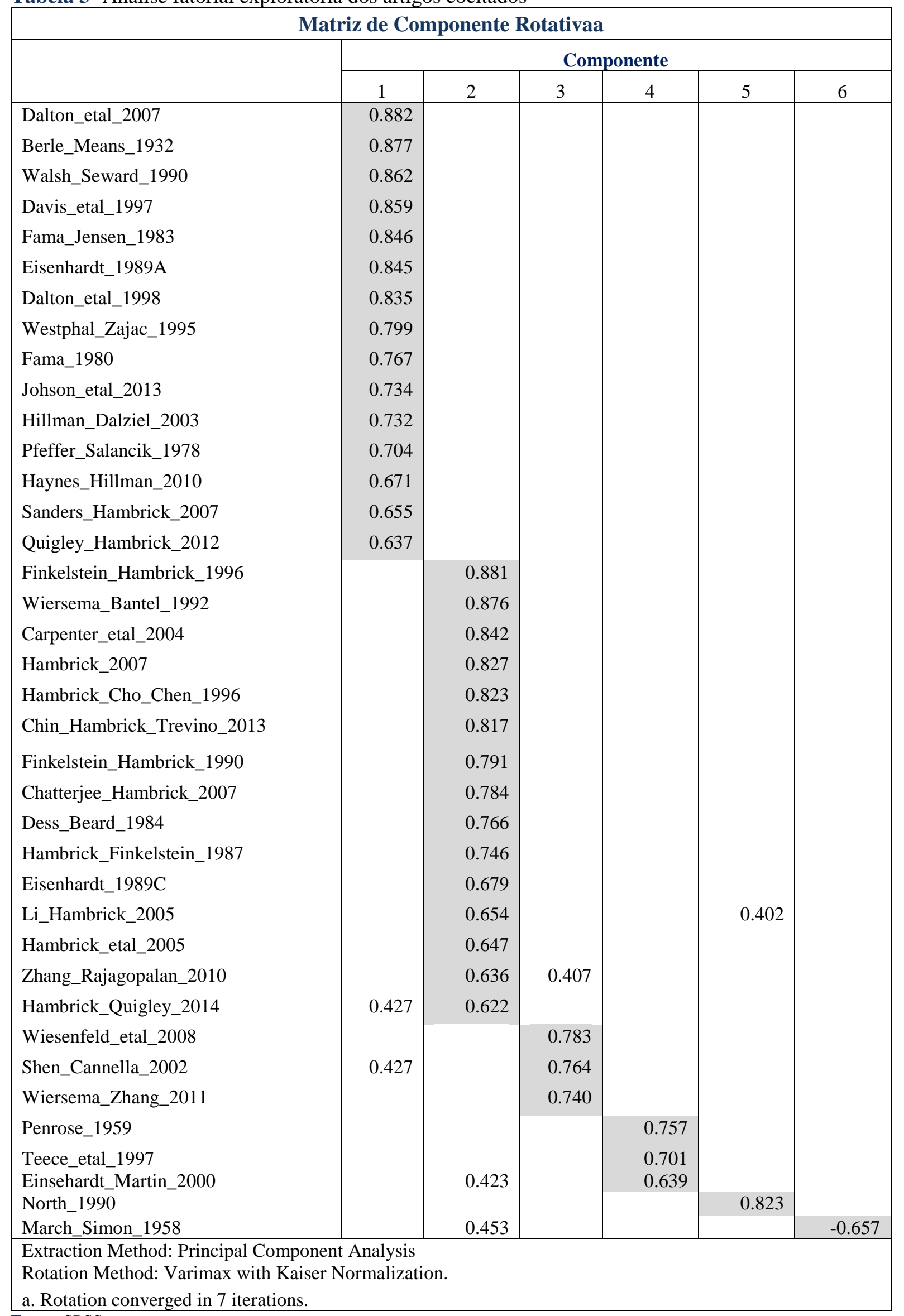
Fonte: SPSS. 
O primeiro fator identificado contempla, essencialmente, as questões de relacionamento, interação e influência entre o conselho de administração e o TMT, com destaque para o papel do CEO. Sua base teórica comum inclui o livro de Bearle e Means (1932), um texto clássico sobre a governança corporativa no contexto institucional norte-americano. À época, o texto já regulava a separação entre propriedade (difusa, detida por grande número de acionistas não controladores) e o controle, exercido pelo CEO e o TMT, além dos artigos seminais de Fama (1980) e de Fama e Jensen (1983) sobre a teoria da agência. Os artigos de Fama e Jensen também são alvo de atenção de Eisenhadt (1989), em seu artigo de revisão, e de Dalton, Hitt, Certo e Dalton (2007), em artigo que trata das abordagens propostas para mitigação do problema do comportamento oportunista dos gestores. A fundação teórica deste fator inclui, finalmente, o artigo seminal de Pfeffer e Salancik (1978), que aborda o controle (externo) das organizações, sob a perspectiva da dependência de recursos. Sobre essa base, diversos artigos deste fator abordam aspectos do conselho de administração, compreendendo o estudo dos efeitos da demografia do conselho sobre sua eficácia na governança (Dalton, Daily, Ellstrand, \& Johnson, 1998) e sobre o seu capital social e humano (Johnson, Schnatterl \& Hill, 2013). O conceito de capital (humano e social) do conselho é detalhado por Haynes \& Hillman (2010), em artigo que também estabelece a relação entre o capital do conselho e a mudança estratégica. Hilman, em coautoria com Dalziel (2003), procura integrar abordagens anteriores, como a da teoria da agência e da dependência de recursos, para explicar as funções desempenhadas pelos conselhos no monitoramento dos gestores e na provisão de recursos. Outros artigos avançam além da discussão sobre aspectos do conselho para a consideração da sua relação com o CEO e o TMT. O já citado artigo de Haynes e Hillman (2010) reconhece o poder moderador do CEO na relação entre o capital do conselho e a mudança estratégica e o artigo de Quigley e Hambrick (2012) trata da influência do antigo CEO mantido como presidente do conselho sobre a discrição gerencial do novo CEO. O estudo de Westphal e Zajac (1995) versa sobre a influência do CEO na escolha de membros do conselho. Um grupo final de artigos deste fator trata, especificamente, dos mecanismos à disposição dos conselhos para incentivo e controle do comportamento dos CEOs e TMTs. Tais artigos abordam os seus reflexos sobre o risco assumido por estes últimos e os meios por meio dos quais os gestores procuram evadi-los (Sanders \& Hambrick, 2007; Walsh \& Seward, 1990). Esse fator é responsável pela explicação de $27,48 \%$ da variação na amostra de artigos.

O segundo fator contempla diversos estudos que consolidam e avançam o conhecimento sobre a UET, em especial sobre os aspectos demográficos ou, diretamente, dos quadros cognitivos dos TMTs e dos CEOs e das suas implicações sobre o desempenho das empresas. Do fator faz parte o artigo de revisão de Carpenter, Geletkanycz e Sanders (2004), no qual os autores destacam a necessidade de definição mais precisa dos conceitos de "alto escalão" e de "time", e instigam os pesquisadores da UET a ultrapassarem os limites da demografia nos estudos do TMT. Outro artigo de revisão que integra este fator é o de Hambrick (2007), no qual o autor comenta o desenvolvimento recente na UET (distribuição do poder intra-TMT e integração comportamental ou feudos dentro do TMT). Hambrick (2007) também destaca novos desafios a serem investigados, como o a "abertura da caixa preta" do TMT (ver Lawrence, 
1997), e o estudo das diferenças entre países e culturas e dos efeitos de sistemas de remuneração. Os demais artigos do fator abordam, em parte, questões de pesquisa indicadas nos artigos de revisão já citados, incluindo: a) o efeito do narcisismo do CEO sobre o desempenho e as opções estratégicas das empresas (Chatterjee \& Hambrick, 2007); b) a influência da ideologia política do CEO sobre as práticas de responsabilidade social da empresa (Chin, Hambrick \& Treviño, 2013); c) a relação entre a duração do mandato dos executivos e a persistência de estratégias, em conformidade com tendências centrais da indústria (Finkelstein \& Hambrick, 1990); e d) a influência da heterogeneidade na composição do TMT e os movimentos competitivos das empresas (Hambrick, Cho \& Chen, 1996).

A influência do alto escalão das empresas sobre a mudança estratégica, em particular, é objeto de dois estudos deste fator: o de Wiersema \& Bantel (1992), que relaciona a mudança estratégica à demografia do TMT, e o de Zhang \& Rajagopalan (2010), que a relaciona à origem (interna ou externa) do CEO. Os estudos que conceituam os principais "efeitos moderadores" da UET, destacados por Hambrick (2007) como avanços importantes da teoria, também fazem parte deste fator: a MD é tratada no trabalho de Hambrick e Finkelstein (1987) e as demandas sobre o trabalho do executivo, no de Hambrick, Finkelstein e Mooney (2005). Um último conjunto de estudos deste fator tem seu foco no refinamento do poder explicativo da UET, para além dos aspectos demográficos e de generalizações, que consideram, de forma indiferenciada, todo o TMT. Este é o caso do artigo de Hambrick e Quigley (2014), que estuda o efeito do CEO sobre o desempenho da empresa em contextos de alta, média e baixa MD. Também é o caso do artigo de Li e Hambrick (2005), que identifica grupos e facções (factional groups) dentro de equipes de executivos, cujo estudo (na visão dos autores) demanda a identificação de outras métricas para avaliação da sua diversidade demográfica, além das utilizados até então. Esse fator explica $25,91 \%$ da variação na amostra de artigos.

O terceiro fator tem seu foco sobre as consequências do desempenho organizacional insatisfatório para o time de executivos de primeiro nível; mais especificamente, os artigos deste fator tratam da dispensa do CEO e do TMT. O artigo de Shen e Cannella (2002) aborda os antecedentes da dispensa de CEOs, seguida pela nomeação de um novo CEO, escolhido entre os executivos da própria organização. O artigo de Wiersema e Zhang (2011), por sua vez, aborda a influência de analistas financeiros externos na certificação e legitimação das avaliações do conselho quanto à competência do CEO e, em caso de desempenho insatisfatório, na sua dispensa. O terceiro e último artigo deste fator, de autoria de Wiesenfeld, Wurthmann e Hambrick (2008), expande o foco dos anteriores no CEO para as elites (executivos e conselheiros) e trata da sua estigmatização e desvalorização, em caso de desempenho insatisfatório de suas empresas. Para os autores, esse processo se desvia bastante do que seria esperado no caso de ser explicado apenas pelos conceitos de racionalidade e justiça propostos pela teoria da agência. Esse fator explica 7,56\% da variação total da amostra.

$\mathrm{O}$ quarto fator contempla estudos que focalizam duas abordagens da estratégia empresarial fortemente relacionadas: a visão baseada em recursos (resource-based view - RBV) e a das capacidades dinâmicas (dynamic capabilities - DC). Inclui o livro de Penrose (1959), que é considerado a inspiração 
inicial para a RBV e é citado no artigo seminal de Teece, Pisano e Shuen (1977) sobre DC, que também faz parte desse fator. O terceiro e último estudo desse fator é o artigo de Eisenhardt e Martin (2000), no qual os autores identificam o papel dos gestores na criação das rotinas organizacionais e estratégicas, por meio das quais a base de recursos de uma empresa é integrada e recombinada, dando origem às capacidades dinâmicas. Este fator explica $6,18 \%$ do total da variação na amostra de artigos analisados.

O quinto fator compreende apenas uma obra, o livro de North (1990), que apresenta um framework analítico para o entendimento da forma como as instituições e a mudança institucional afetam o desempenho das economias nacionais. Este é um ponto também explorado pelos pesquisadores da UET, quando consideram efeitos de culturas e instituições nacionais sobre os TMTs. Esse fator explica $3,68 \%$ da variação na amostra.

Finalmente, o sexto e último fator também inclui apenas um livro, o de March e Simon (1958). A obra é seminal da teoria comportamental da empresa, que destaca a importância dos administradores na tomada de decisão estratégica e que representa a fundação sobre a qual a UET se apoia. Este fator explica $3,53 \%$ da variação na amostra.

\section{Cocitações - mapeamento de rede}

A Figura 3 ilustra o mapeamento de rede dos principais trabalhos cocitados, feita com o uso do software UCINET. Os trabalhos identificados por um círculo compõem o primeiro fator. O segundo fator é representado por um quadrado. $\mathrm{O}$ triângulo com vértice para cima representa o terceiro fator. $\mathrm{O}$ triângulo com o vértice para baixo representa o quarto fator. O losango representa o quinto fator e, finalmente, o círculo dentro de um quadrado representa o sexto fator. Os trabalhos identificados mais ao centro apresentam grau de centralidade mais elevado em relação aos outros trabalhos, servindo, portanto, de base para as demais pesquisas. A espessura das linhas representa a quantidade de vezes em que os trabalhos se conectam 
Figura 3 - Mapeamento da rede de trabalhos cocitados

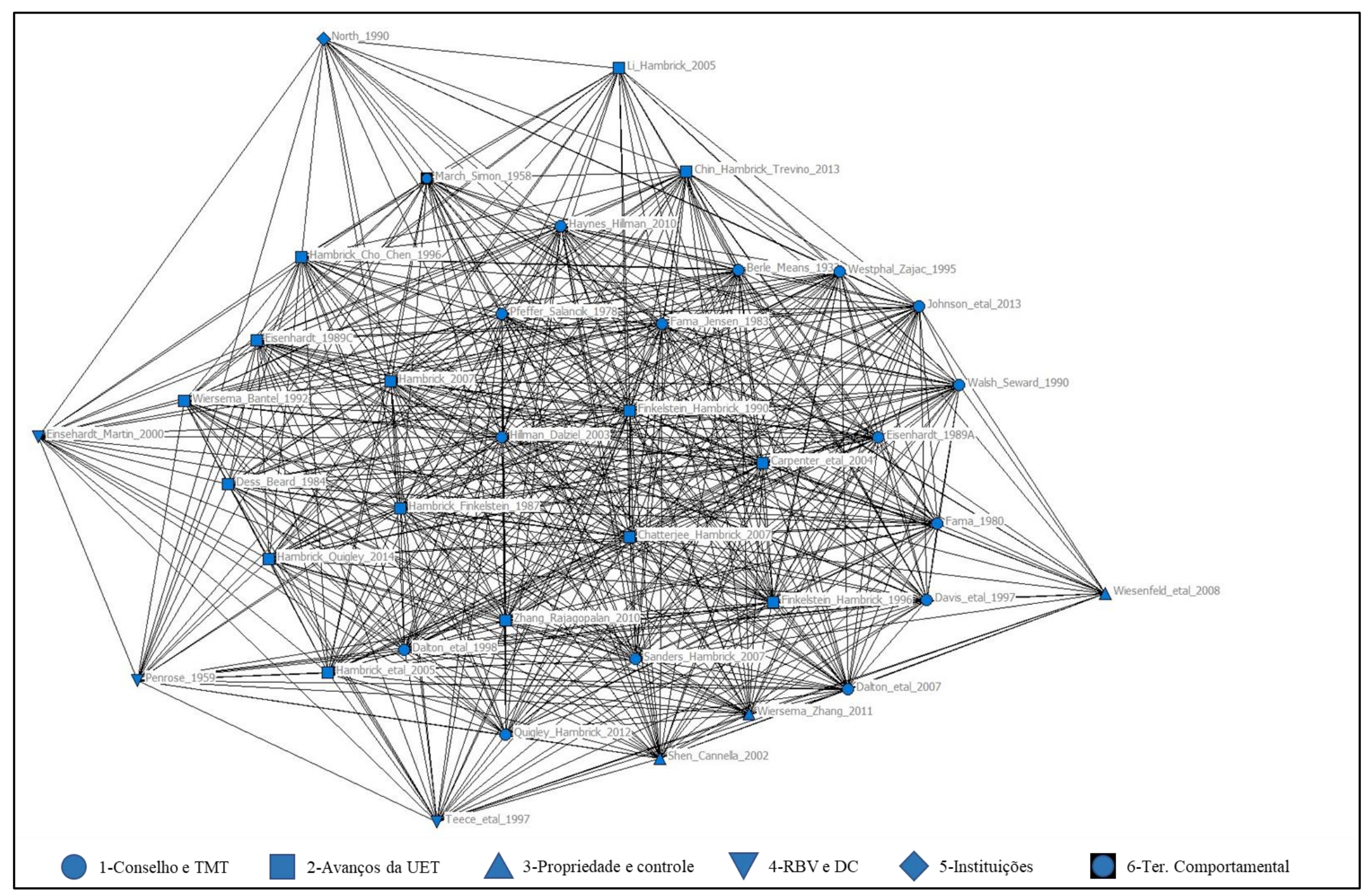

Fonte: Ucine. 
A Figura 3 aponta para a centralidade de alguns dos trabalhos cocitados dos fatores 1 e 2, como os artigo de revisão e consolidação da UET de Carpenter, Geletkanycz e Sanders (2004) e de Hambrick (2007). Além desses, também apontam para a centralidade os artigos que tratam da relação entre atributos do TMT (entendido de uma forma ampliada, isto é, envolvendo também o conselho) e o desempenho organizacional, moderado, em alguns casos, pela MD (Hambrick \& Finkelstein, 1987; Finkelstein \& Hambrick, 1990; Hillman \& Dalziel, 2003; Chatterjee \& Hambrick, 2007). Todos os artigos posicionados no entorno imediato do centro da rede são também integrantes dos fatores 1 e 2 . Esse posicionamento parece indicar que os temas envolvendo a relação entre o conselho e o TMT e os estudos que promovem o avanço do conhecimento e do poder explicativo da UET são os de maior influência sobre os estudos que citam Hambrick. Todos os artigos classificados nos fatores 3, 4, 5 e 6 estão na periferia da rede ou próximos dela, indicando que sua contribuição, embora importante, não é central.

\section{Discussão}

Este estudo bibliométrico indicou que os trabalhos de Hambrick continuam relevantes para os pesquisadores que se dedicam a estudar as características dos integrantes do TMT e o seu reflexo sobre desempenho das organizações. O número de artigos que citam a obra de Hambrick tem crescido ao longo dos anos, e as obras centrais do autor sobre a UET se mantêm como as mais citadas. O artigo seminal no qual Hambrick formulou, pela primeira vez, os conceitos básicos da teoria é, destacadamente, o mais citado dos seus trabalhos, o que parece confirmar que sua relevância perdura mesmo passados 35 anos de sua publicação. Merece destaque o fato de que, entre as revistas que publicaram o maior número de artigos que fazem referência à UET (conforme Tabela 2), estão algumas das publicações de mais elevado fator de impacto na Administração. Esse fato atesta, além do número crescente de referências ao longo dos anos, que a teoria se mantém relevante para os pesquisadores e com capacidade de produção de elevada qualidade neste campo das Ciências Sociais.

Esta análise de cocitações, que teve seu foco sobre artigos publicados recentemente (nos anos de 2016 e 2017), aponta para um aumento da abrangência dos estudos sobre a UET e da inter-relação entre esses estudos sobre a UET e outras correntes da administração estratégica e da organização. O conceito de TMT se amplia, passando a incorporar o conselho e administração e, ao se ampliar, incorpora ao escopo dos estudos da UET questões associadas à separação entre propriedade e controle e dá a essas questões um tratamento que contempla a demografia desse TMT ampliado (ver Johnson et al., 2013; Quigley \& Hambrick, 2012).

Outro grupo importante de estudos, que corresponde ao segundo fator identificado na análise fatorial, aprofunda a pesquisa sobre diversos aspectos da demografia do TMT e sobre a relação entre essa demografia e o desempenho organizacional, avançando além das proposições originais da teoria e ampliando o poder explicativo da UET. É importante notar que esse aprofundamento ultrapassa a 
validação de relações entre o desempenho e aspectos demográficos tradicionais. Esses aspectos estão relacionados com o tempo de mandato ou com a experiência funcional prévia dos executivos, incorporando a esse estudo aspectos contextuais que, em alguns casos, examinam diretamente os quadros cognitivos dos integrantes do TMT (Chatterjee \& Hambrick, 2007; Hambrick \& Quigley, 2014).

A proposta original da UET (ilustrada pela Figura 1) dá ideia de uma sequência linear, lógica, que tem sua origem na situação objetiva da organização, que é interpretada pelo TMT a partir de sua base cognitiva, valores e percepções. Essa intepretação orienta as escolhas estratégicas dos executivos e, em última instância, determina o desempenho da organização. Alguns dos artigos mais cocitados percorrem um caminho inverso, pois estudam o efeito do desempenho (insatisfatório) da empresa sobre a avaliação das escolhas estratégicas dos executivos e da sua eficácia gerencial e, em consequência, dos quadros cognitivos utilizados para interpretar a realidade. . Esses estudos abordam os antecedentes (Shen \& Cannella, 2002; Wiersema \& Zhang, 2011) e efeitos (Wiesenfeld, Wurthmann \& Hambrick, 2008) da dispensa de executivos de alto escalão.

A conexão entre as abordagens da RBV/DC e a UET é observada nos estudos classificados no quarto fator identificado na análise fatorial. Essa relação se manifesta, num primeiro nível, no reconhecimento do papel que os gestores da organização têm na integração e recombinação da base de recursos da empresa, que dá origem às suas capacidades dinâmicas, papel que é influenciado por seus quadros cognitivos. Num segundo nível, essa conexão se dá pela identificação dos próprios executivos da organização como recursos valiosos, raros, inimitáveis e não substituíveis, instrumentais para a concepção e implementação de estratégias, que não podem ser copiadas facilmente pelas empresas concorrentes e que permitem, assim, alcançar vantagem competitiva sustentada (Eisenhardt \& Martin, 2000).

Finalmente, as cocitações permitem identificar relações significativas entre a UET e duas outras correntes teóricas da administração. A primeira corrente considera a teoria comportamental, por meio do livro de March e Simon (1958), que estabelece as bases sobre as quais Hambrick e Mason (1984) construíram a UET. O outro relacionamento importante é com o estudo das instituições e das mudanças institucionais em diferentes países, pela via indireta da MD. De um estágio inicial, no qual as fontes da MD eram associadas ao setor econômico, as pesquisas nesse tema evoluíram para considerar também a sua variação em diferentes contextos nacionais. Esses contextos são consistentes com as diferenças entre instituições formais e informais nos diferentes países, como tradições legais, estrutura de controle das empresas, governança e papel dos conselhos e valores culturais (Finkelstein, Hambrick, \& Cannella, 2009).

\section{Conclusão}

Por meio da aplicação de técnicas bibliográficas de citação e cocitação, este trabalho identificou a contribuição dos trabalhos de Donald C. Hambrick para o desenvolvimento teórico e empírico da 
pesquisa em UET e de sua influência sobre a obra de outros autores e linhas de investigação no campo da Administração. Como toda pesquisa, este trabalho tem algumas limitações. A base de citações usada para a busca de citações aos artigos de Hambrick sobre UET foi a ISI Web of Knowledge, considerada de alto valor pela comunidade científica por cobrir somente as revistas internacionais ou regionais consideradas top tier (Torres-Salinas, Robison-Garcia, Campanario, \& López-Cózar, 2014). Os critérios declaradamente seletivos adotados por este serviço para a escolha dos periódicos em sua Core Collection (Testa, 2016) têm, como consequência, um número menor de artigos indexados. Uma pesquisa baseada em serviços de indexação menos seletivos identificaria, possivelmente, um número superior de citações ao autor, cuja análise, por sua vez, poderia apontar conclusões distintas daquelas alcançadas neste estudo.

A opção por restringir a pesquisa a citações da obra de Hambrick sobre UET somente aos artigos por ele publicados em revistas acadêmicas revisadas por pares também representa uma limitação importante, ao eliminar da busca parte de sua produção sobre o tema. Dentre as obras excluídas, por exemplo, encontra-se o capítulo para um livro escrito por Hambrick e Finkelstein (1987), em que os autores formulam (possivelmente pela primeira vez) o conceito da MD. A inclusão deste e de outros capítulos e livros poderia, potencialmente, identificar novas citações e cocitações, alterando os resultados aqui reportados.

Ambas as técnicas bibliométricas empregadas sofrem de vieses associados ao tempo para a acumulação de citações. Novos trabalhos dispõem de menos tempo para acumular citações, o que privilegia artigos mais antigos, se o uso da contagem de citações é usado como critério para a influência de uma obra (Zupic \& Cater, 2015). Da mesma forma, embora a análise de cocitações seja um instrumento relevante para filtrar as obras mais importantes, também privilegia os artigos que dispõem de mais tempo para angariar citações, o que a torna pouco útil para a identificação de frentes de pesquisa atuais (Zupic \& Cater, 2015).

Como sugestões para pesquisa futura, destacamos a incorporação de uma análise de pareamento (bibliographic coupling), a partir de referências buscadas em novas bases de indexação e incluindo novas obras de Hambrick às análises aqui realizadas. Essas novas análises poderiam contribuir para um melhor entendimento e posicionamento da contribuição do autor e da UET para a ciência da Administração e confirmação da sua relevância para linhas de pesquisas atuais. Em particular, uma pesquisa usando o acoplamento bibliográfico seria "especialmente útil para o mapeamento de frentes de pesquisa e campos emergentes, nos quais os dados de citações ainda não existem ou subcampos menores que não são citados com a frequência necessária para produzir conexões confiáveis numa análise de cocitações" (Zupic \& Cater, 2015, p. 435).

\section{Referências}

Abrahamson, E., \& Hambrick, D. C. (1997). Attentional homogeneity in industries: the effect of discretion. Journal of Organizational Behavior, 18(Special Issue), 513-532. 
Aiken, L. S., \& West, S. G. (1991). Multiple regression: testing and interpreting interactions. Thousand Oaks, CA: Sage.

Bar-Ilan, J. (2014). Citations to the "introduction to informetrics" indexed by WOS, Scopus and Google Scholar. Scientometrics, 82(3), 495-506.

Berle, A. A., Jr., \& Means, G. C. (1932). The modern corporation and private property. New York: McMillan.

Briscoe, F. Chin, M. K., \& Hambrick, D. C. (2014). CEO ideology as an element of the corporate opportunity structure for social activists. Academy of Management Journal, 57(6), 1786-1809.

Cannella, A., \& Hambrick, D. C. (1993). Effects of executive departures on the performance of acquired firms. Strategic Management Journal, 14(Special Issue), 137-152.

Carpenter, M. A., Geletkanycz, M. A., \& Sanders, W. G. (2004). Upper echelons research revisited: antecedents, elements and consequences of Top Management Team composition. Journal of Management, 30(6), 749-778.

Chatterjee, A., \& Hambrick, D. C. (2007). It's all about me: narcissistic chief executive officers and their effects on company strategy and performance. Administrative Science Quarterly, 52(3), 351386.

Chatterjee, A., \& Hambrick, D. C. (2011). Executive personality, capability cues, and risk taking: how narcissistic CEOs react to their success and stumbles. Administrative Science Quarterly, 56(12), 202-237.

Chen, G., \& Hambrick, D. C. (2012). CEO replacement in turnaround situations: executive (mis)fit and its performance implications. Organization Science, 23(1), 225-243.

Chen, G., Hambrick, D. C., \& Pollock, T. G. (2008). Puttin' on the Ritz: pre-IPO enlistment of prestigious affiliates as deadline-induced remediation. Academy of Management Journal, 51(5), 954-975.

Chen, G., Treviño, L. K., \& Hambrick, D. C. (2009). CEO elitist association: toward a new understanding of an executive behavioral pattern. Leadership Quarterly, 20(3), 316-328.

Child, J. (1972). Organizational structure, environment and performance: the role of strategic choice. Sociology, 6(1), 1-22.

Child, J. (1997). Strategic Choice in the analysis of action, structure, organizations and environment: retrospect and prospect. Organization Studies, 18(1), 43-76.

Chin, M. K., Hambrick, D. C., \& Treviño, L. K. (2013). Political ideologies of CEOs: the influence of executives' values on corporate social responsibility. Administrative Science Quarterly, 58(2), 197 232.

Cho, T. S., \& Hambrick, D. C. (2006). Attention as the mediator between top management team and strategic change: the case of airline deregulation. Organization Science, 17(4), 453-469.

Crossland, C., \& Hambrick, D. C. (2007). How national systems differ in their constraints on corporate executives: A study of CEO effects in three countries. Strategic Management Journal, 28(8), 767-789

Crossland, C., \& Hambrick, D. C. (2011). Differences in managerial discretion across countries: how nation-level institutions affect the degree to which CEOs matter. Strategic Management Journal, 32(8), 797-819.

Crossland, C., Zyung, J., Hillier, N. J., \& Hambrick, D. C. (2014). CEO career variety: effects on firmlevel strategic and social novelty. Academy of Management Journal, 57(3), 652-674.

Cyert, R. M., \& March, J. G. (1963). A behavioral theory of the firm. Englewood Cliffs, N. J.: Prentice-Hall.

Dalton, D. R., Daily, C. M., Ellstrand, A. E., \& Johnson, J. L. (1998). Meta-analytic reviews of board composition, leadership structure, and financial performance. Strategic Management Journal, 9(3), 269-290.

Dalton, D. R., Hitt, M. A., Certo, S. T., \& Dalton, C. M. (2007). The fundamental agency problem and Its mitigation: independence, equity, and the market for corporate control. Academy of Management Annals, 1, 1-64.

Davis, J. H., Schoorman, F. D., \& Donaldson, L. (1997). Toward a stewardship theory of management. Academy of Management Review, 22(1), 20-47.

Dess, G. D., \& Beard, D. W. (1984). Dimensions of organizational task environments. Administrative Science Quarterly, 29(1), 52-73. 
DiMaggio, P., \& Powell, W. (1983). The iron cage revisited: institutional isomorphism and collective rationality in organizational fields. American Sociological Review, 48(2), 147-160.

D'Aveni, R. A. (1990). Top management prestige and organizational bankruptcy. Organizational Science, 1(2), 121-142.

Eisenhardt, K. (1989a). Agency theory: an assessment and review. Academy of Management Review, 14(1), 57-74.

Eisenhardt, K. (1989). Making fast strategic decisions in high-velocity environments. Academy of Management Journal, 32(3), 543-576.

Eisenhardt, K. M., \& Bourgeois, L. J. (1988). Politics of strategic decision making in high-velo-city environments: toward a midrange theory. Academy of Management Journal, 31(4), 737-770.

Eisenhardt, K., \& Martin, J. A. (2000 ). Dynamic capabilities: what are they? Strategic Management Journal, 21(10-11), 1105-1121.

Fama, E. F. (1980). Agency problems and the theory of the firm. Journal of Political Economy, 88(21), 288-307.

Fama, E. F., \& Jensen, M. C. (1983). Separation of ownership and control. Journal of Law \& Economics, 26(2), 301-325.

Ferreira, M. A. S. P. V., Pinto, C. S. F., Serra, F. A. R., \& Santos, J. C. (2013). A bibliometric study of John Dunning's contribution to international business research. Revista Brasileira de Gestão de Negócios, 15(46), 56-75

Finkelstein, S., \& Hambrick, D. C. (1988). Chief executive compensation: a synthesis and reconciliation. $\quad$ Strategic Management Journal, 9(6), 543-558.

Finkelstein, S., \& Hambrick, D. C. (1989). Chief executive compensation: a study of the intersection of markets and political processes. Strategic Management Journal, 10(2), 121-134.

Finkelstein, S., \& Hambrick, D. C. (1990). Top management team tenure and organizational outcomes: the moderating role of managerial discretion. Administrative Science Quarterly, 35(3), 484-503.

Finkelstein, S., \& Hambrick, D. C. (1996). Strategic leadership: top executives and their effects on organizations. Cincinnati, OH: South-Western College Pub.

Finkelstein, S., Hambrick, D. C., \& Canella, A. A., Jr. (2009). Strategic leadership: theory and research on executives, top management teams, and boards. New York: Oxford University Press.

Fredrickson, J. W., Hambrick, D. C., \& Baumrin, S. (1988). A model of CEO dismissal. Academy of Management Review, 13(2), 255-270.

Garfield, E. (1998). Random thoughts in Citationology: its theory and practice. Scientometrics, 43(1), 69-76.

Gavetti, G., Levinthal, D., \& Ocasio, W. (2007). Neo-Carnegie: the Carnegie School's past, present and reconstructing for the future. Organization Science, 18(3), 523-536.

Geletkanycz, M. A., \& Hambrick, D. C. (1997). The external ties of top executives: implications for strategic choice and performance. Administrative Science Quarterly, 42(4), 654-681.

Gerstner, W. C., Konig, A., Enders, A., \& Hambrick, D. C. (2013). CEO narcissism, audience engagement, and organizational adoption of technological discontinuities. Administrative Science Quarterly, 58(2), 257-291.

Gupta, A., Briscoe, F., \& Hambrick, D. C. (2017). Red, blue, and purple firms: organizational political ideology and corporate social responsibility. Strategic Management Journal, 38(5), 1018-1040.

Hair, J. F., Jr., Black, W. C., Babin, B. J., \& Tatham, R. L. (2009). Análise multivariada de dados, $6^{\text {a }}$ edição. Porto Alegre: Bookman.

Hambrick, D. C. (1981a). Environment, strategy, and power within top management teams. Administrative Science Quarterly, 26 (2), 253-275.

Hambrick, D. C. (1981b). Specialization of environmental scanning within top management teams. Journal of Management Studies, 18(3), 299-320.

Hambrick, D. C. (1981c). Strategic awareness within top management teams. Strategic Management Journal, 2(3), 263-279.

Hambrick, D. C. (1982). Environmental scanning and organizational strategy. Strategic Management Journal, 3(2), 159-174.

Hambrick, D. C. (2007). Upper echelons theory: an update. Academy of Management Review, 32(2), 334-343. 
Hambrick, D. C., \& Abrahamson, E. (1995). Assessing the amount of managerial discretion in different industries. Academy of Management Journal, $38(5$ ), 1427-1441.

Hambrick, D. C., Cannella, A. A. (1993). Relative standing: a framework for understanding departures of acquired executives. Academy of Management Journal, 36(4), 733-762.

Hambrick, D. C., \& Cannella, A. (2004). CEOs who have COOs: contingency analysis of an unexplored structural form. Strategic Management Journal, 25(10), 959-979.

Hambrick, D.C., Cho, T. S., \& Chen, M. J. (1996), The influence of top management team heterogeneity on firms' competitive moves. Administrative Science Quarterly, 41(4), 659-684.

Hambrick, D. C., Davison, S. C., Snell, S. A., \& Snow, C. C. (1998). When groups consist of multiple nationalities: towards a new understanding of the implications. Organization Studies, 19(2), 181205.

Hambrick, D. C., \& D'Aveni, R. (1992). Top management team deterioration as part of the downward spiral of large bankruptcies. Management Science, 38(10), 1445-1466.

Hambrick, D. C., \& Finkelstein, S. (1987). Managerial discretion: a bridge between polar views on organizations. In B. Staw (Ed.). Research in Organizational Behavior (Vol. 9, pp. 369-406).

Beverly Hill: JAI Press.

Hambrick, D. C., \& Finkelstein, S. (1995). The effects of ownership structure on conditions at the top: the case of CEO pay raises. Strategic Management Journal, 16(3), 175-193.

Hambrick, D. C., Finkelstein, S., \& Mooney, A. (2005). Executive job demands: new insights for explaining strategic decisions and leader behaviors. Academy of Management Review, 30(3), 472491.

Hambrick, D. C., \& Fukutomi, G. (1991). Seasons of a CEO's tenure. Academy of Management Review, 16(4), 719-742

Hambrick, D. C., Geletkanycz, M., \& Fredrickson, J. (1993). Top executive commitment to the status quo: some tests of its determinants. Strategic Management Journal, 14(6), 401-418.

Hambrick, D. C., Humphrey, S. E., \& Gupta, A. (2015). Structural interdependence within top management teams: a key moderator of upper echelons predictions. Strategic Management Journal, 36(3), 449-461.

Hambrick, D. C., Li, J., Xin, K., \& Tsui, A. S. (2001). Compositional gaps and downward spirals in international joint venture management groups. Strategic Management Journal, 22(11), 1033-1053.

Hambrick, D. C., \& Mason, P. A. (1984). Upper echelons: the organization as reflection of its top managers. Academy of Management Review, 9(2), 193-206.

Hambrick, D. C., Misangyi, V. F., \& Park, C. A. (2015). The quad model for identifying a corporate director's potential for effective monitoring: toward a new theory of board sufficiency. Academy of Management Review, 40(3), 323-344.

Hambrick, D. C., \& Quigley, T. J. (2014). Toward more accurate contextualization of the CEO effect on firm performance. Strategic Management Journal, 35(4), 473-491.

Hanisch, B., \& Wald, A. (2012). A bibliometric view on the use of contingency theory in project management research. Project Management Journal, 43(3), 4-23.

Hannan, M., \& Freeman, J. (1977). The population ecology of organizations. American Journal of Sociology, 82(5), 929-964.

Harrigan, R. H. (1980). Strategy formulation in declining industries. Academy of Management Review, 5(4), 499-604.

Haynes, K. T., \& Hillman, A. (2010). The effect of board capital and CEO power on strategic change. Strategic Management Journal, 31(11), 1145-1163.

Hayward, M., \& Hambrick, D. C. (1997). Explaining the premiums paid for large acquisitions: evidence of CEO hubris. Administrative Science Quarterly, 42(1), 103-127.

Henderson, A. D., Miller, D., \& Hambrick, D. C. (2006). How quickly do COEs become obsolete? Industry dynamism, CEO tenure, and company performance. Strategic Management Journal, 27(5), 447-460.

Hillier, N., \& Hambrick, D. C. (2005). Conceptualizing executive hubris: the role of (hyper-) core selfevaluations in strategic decision-making. Strategic Management Journal, 26(4), 297-319.

Hillman, A. J., \& Dalziel, T. ( 2003). Boards of directors and firm performance: integrating agency and resource dependence perspectives. Academy of Management Review, 28(3), 383-396. 
Johnson, S. G., Schnatterly, K., \& Hill, A. D. (2013). Board composition beyond independence: social capital, human capital, and demographics. Journal of Management, 39(1), 232-262.

Lawrence, B.S. (1997). 1997. The black box of organizational demography. Organization Science, $8(1), 1-22$.

Li, J., \& Hambrick, D. C. (2005). Factional groups: a new vantage on demographic faultlines, conflict and disintegration in work teams. Academy of Management Journal, 48(5), 794-813.

Kilduff, M. (2007). Celebrating thirty years of theory publishing in AMR: award-winning articles from the first two decades revisited. Academy of Management Review, 22(2), 332-333.

McCain, K. (1990). Mapping authors in intellectual space: a technical overview. Journal of the American Society for Information Science, 41(6), 433-443.

March, J. G. (1991). Exploration and exploitation in organizational learning. Organization Science, 2(1), 71-87.

March, J. G., \& Simon, H. A. (1958). Organizations. New York: Wiley.

Michel, J. G., \& Hambrick, D. C. (1992). Diversification posture and the characteristics of the top management team. Academy of Management Journal, 35(1), 9-37.

North, D. C. (1990). Institutions, institutional change and economic performance. Cambridge, UK: Cambridge University Press.

Nosella, a., Cantarello, S., \& Filippini, R. (2012). The intellectual structure of organizational ambidexterity: a bibliographic investigation into the state of the art. Strategic Organization, 10(4), 450-465.

Oppong, S. (2014). Upper echelons theory revisited: the need for a change from causal description to causal explanation. Management: Journal of Contemporary Management Issues, 19(2), 169-183.

Penrose, E. (1959). The theory of the growth of the firm. New York: Wiley.

Pfeffer, J., \& Salancik, G. R. (1978). The external control of organizations: a resource dependence perspective. New York: Harper \& Row.

Podsakoff, P. M., MacKenzie, S. B., Lee, J. Y., \& Podsakoff, N. P. (2003). Common method biases in behavioral research: a critical review of the literature and recommended remedies. Journal of Applied Psychology, 88(5), 879-903.

Pollock, T. G., Chen, G., Jackson, E. M., \& Hambrick, D. C. (2010). How much prestige is enough? Assessing the value of multiple types of high-status affiliates for young firms. Journal of Business Venturing, 25(1), 6-23.

Porter, M. E. (1980). Competitive strategy: techniques for analyzing industries and competitors. New York: The Free Press.

Potter, W. G. (1981). Lotka's law revisited. Library Trends, 30(1):21-39.

Quigley, T. J., \& Hambrick, D. C. (2012). When the former CEO stays on as board chair: effects on successor discretion, strategic change, and performance. Strategic Management Journal, 33(7), 834859.

Quigley, T. J., \& Hambrick, D. C. (2015). Has the "CEO effect" increased in recent decades? A new explanation for the great rise in America's attention to corporate leaders. Strategic Management Journal, 36(6), 821-830.

Ramos-Rodríguez, A. R., \& Ruíz-Navarro, J. (2004). Changes in the intellectual structure of strategic management research: a bibliometric study of the Strategic Management Journal. Strategic Management Journal, 25(10), 981-1004.

Sanders, W. G., \& Hambrick, D. C. (2007). Swinging for the fences: the effects of CEO stock options on company risk-taking and performance. Academy of Management Journal, 50(5), 1055-1078.

Shen, W., \& Cannella, A. A. (2002). Power dynamics within top management and their impacts on CEO dismissal followed by inside succession. Academy of Management Journal, 45(6 ), 1195-1206.

Siegel, P. A., \& Hambrick, D. C. (2005). Pay disparities within top management groups: evidence of harmful effects on performance of high-technology firms. Organization Science, 16(3), 259-274.

Small, H. (1973). Co-citation in the scientific literature: a new measure of the relationship between two documents. Journal of the American Society for information Science, 24(4), 265-269.

Snow, C. C., \& Hambrick, D. C. (1980). Measuring organizational strategies: some theoretical and methodological problems. Academy of Management Review, 5(4), 527-538. 
Teece, D. J., Pisano, G., \& Shuen, A. (1997). Dynamic capabilities and strategic management. Strategic Management Journal, 18(7), 509-533.

Testa, J. (2016). Journal selection process. Recuperado em 23 de novembro de 2017, de: https://clarivate.com/essays/journal-selection-process/.

Torres-Salinas, D., Robinson-Garcia, N., Campanario, J. M., \& López-Cózar, E. D. (2014). Coverage, field specialisation and the impact of scientific publishers indexed in the Book Citation Index. Online Information Review, 38(1), 24-42.

Vogel, R., \& Güttel, W. H. (2013). The dynamic capabilites view in strategic management: a bibliometric review. International Journal of Management Reviews, 15(4), 426-446.

Walsh, J. P., \& Seward, J. K. (1990). On the efficiency of internal and external corporate-control mechanisms. Academy of Management Review, 15(3), 421-458.

Wangrow, D. B., Schepker, D. J. \& Barker, V. L., III (2015). Managerial discretion: an empirical review and focus on future research directions. Journal of Management, 41(1), 99-135.

Web of Science Core Collection. Recuperado em 10 de outubro de 2017, de http://appswebofknowledge.ez370.periodicos.capes.gov.br/Search.do?product=WOS\&SID=2Ac7ksvr8TGKo QUZWRW\&search_mode=GeneralSearch\&prID=80c74330-76ac-41dd-a975-72eae76553c0.

Westphal, J. D., \& Zajac, E. J. (1995). Who shall govern? CEO/board power, demographic similarity, and new director selection. Administrative Science Quarterly, 40(1), 60-83.

White, D., \& McCain, K. (1998). Visualizing a discipline: An author cocitation analysis of information science, 1972-1995. Journal of the American Society for Information Science,

49(4), 327-355.

Wiersema, M. F., \& Bantel, K. A. (1992). Top management team demography and corporate strategic change. Academy of Management Journal, 35(1), 91-121.

Wiersema, M. F., \& Zhang, Y. (2011). CEO dismissal: the role of investment analysts. Strategic Management Journal, 32(11), 1161-1182.

Wiesenfeld, B. M., Whurtmann, K. A., \& Hambrick, D. C. (2008). The stigmatization and devaluation of elites associated with corporate failures: a process model. Academy of Management Review, 33(1), 231-251.

Wowak, A. J., \& Hambrick, D. C. (2010). A model of person-pay interaction: how executives vary in their responses to compensation arrangements. Strategic Management Journal, 31(8), 803-821.

Wowak, A. J., Hambrick, D. C., \& Henderson, A. D., (2011). Do CEOs encounter within-tenure "settling up"? A multiperiod perspective on executive pay and dismissal. Academy of Management Journal, 54(4), 719-739.

Zhang, Y., \& Rajagopalan, N. (2010). Once an outsider, always an outsider? CEO origin, strategic change, and firm performance. Strategic Management Journal, 31(3), 334-346.

Zupic, I., \& Cater, T. (2015). Bibliometric methods in management and organization. Organizational Research Methods, 18(3), 429-472. 